The different emphases that theorists and teachers place on the product and process of writing in their accounts of how writers construct meaning have been influenced by different traditions of Western thought that have historically been at odds: Whereas the designative tradition focuses on the ways in which artifacts of speech mediate people's thinking, the expressive tradition focuses on the transformation of inner speech to public speech, thus emphasizing the ways in which the activities of speaking and writing promote changes in consciousness. In this article, through the analysis of the writing of a high school senior, it is argued that these two positions are not mutually exclusive, but rather are complementary aspects of a semiotic view on writing. The primary data set is a "situated protocol" - that is, a think-aloud protocol, including both concurrent and retrospective accounts of writing process, conducted over a 4-month period. Through the protocol analysis and analysis of related data, I examine the ways in which this student's writing experiences reveal the interrelated roles of both designative and expressive functions of writing. The analysis also reveals that the writer found the situated protocol itself to be an enduring means of development and reflection and a tool for meditation.

\title{
Personal Growth in Social Context
}

\author{
A High School Senior's Search \\ for Meaning in and Through Writing
}

\author{
PETER SMAGORINSKY \\ University of Oklahoma
}

Those of us who teach the writing process are comfortable with the constant change. This sets us apart from many people in the academic world who teach in a traditional or classical mode, believing there are truths which can be learned and passed on from teacher to student, from generation to generation. Their conception has its attractions; it is the one I was taught. But my life as a writer and as a teacher of writing leads me-as similar experience has led others-to a different tradition which some call developmental or truly humanistic. We do not teach our students rules demonstrated by static models; we teach our stu- 
dents to write by allowing them to experience the process of writing. That is a process of discovery, of using written language to find out what we have to say. . . . There is no way we can tell what our students will need to write in their lives beyond the classroom, but we can give our students a successful experience in the writing process. We can let them discover how writing finds its own meaning. (Murray, 1980, p. 20)

With this declaration, Donald Murray identifies a fundamental conflict in the theory, research, and teaching of composition. To Murray, writers find meaning through the process of writing and in doing so experience developmental changes; writing is a tool that enables people to discover meaning by rendering their thoughts into text. Murray positions himself against approaches to writing that are text centered, arguing that such static approaches do not enable the development of writers and their quest for meaning. Rather, he argues, meaning is constructed through the process of composing, with the meaning of his finished text of secondary importance:

In the months that it has taken me to help this piece of writing find its own meaning I have found new meanings. ... By the time this is published I will, I hope, have moved on. There are those who may be concerned by what they consider inconsistency or disloyalty to my own words. No matter, I have no choice. (Murray, 1980, p. 19)

The changes that writers experience, more than what their words represent, are the source of meaning in writing.

Locating the construction of meaning primarily in the process of writing has both theoretical and pedagogical implications. To Fulwiler (1989), "journals are more useful than formal papers, because writers remain free to respond to their educational world as they see fit; the very nature of expressive discourse implies risk, experimentation, and

Author's Note: This research was supported by a grant from the Office of Research Administration at the University of Oklahoma. The data were analyzed with the help of Chao-Jih Chen, Kevin Dupré, Justin Everett, Peggy Frazier, Patty Reed, Lynda Thompson, Elaine White, and Melissa E. Whiting; Melissa also prepared the final copies of the transcripts for analysis. Thanks to Doug and his teachers for their willing participation in the research and for their thorough openness and cooperation throughout the course of the study and in the years following as I tried to write about it, including their reading of various drafts of the manuscript. Thanks are due as well to Susan Stires and Marcia Farr for their suggestions during the early phase of my efforts to write about Doug. And thanks, of course, to the external reviewers of Written Communication for their extreme patience throughout the development of this article and for their insightful responses to earlier versions of this manuscript. 
failure" (p. 171). Fulwiler contrasts the expressive quality of journal writing with the presumably restrictive constraints of formal writing, thus valuing the meaning produced through the process of writing over the meaning potential of finished texts that follow formal conventions. This contrast, like Murray's, clearly implies a conflict between the meaning potential available through the process of writing and the contemplation of the specific form of finished texts, with a preference for the meaning developed through what Fulwiler calls "expressive" functions of writing.

This dispute in composition studies over the locus of meaning is an incarnation of a clash of traditions that are rooted in Western thought. Wertsch (1996) discusses two philosophical traditions identified by Taylor (1985) that have informed Western understandings of the concept of meaning, arguing that Vygotsky (1987) appeared to draw on both without attention to their putative incompatibility. Wertsch traces the first tradition to the Enlightenment and labels it the "designative" tradition. In this tradition, which Vygotsky relies on in Chapters 5 and 6 of Thinking and Speech, speech and meaning are concerned with referential relationships between signs and objects, with a key process being one's ability to create abstract representations for categories of objects. ${ }^{1}$ Through the use of systems of decontextualized word meanings, people become abstract, rational thinkers. Meaning is thus a function of the relationship between signs (e.g., words and word networks) and the objects they represent to people. The semiotic potential of decontextualization enables abstraction and thus the capacity to categorize, reflect on, and control the world.

The second theoretical tradition affecting Vygotsky's understanding of meaning is the expressive perspective articulated in Chapter 7 of Thinking and Speech. Wertsch (1996) grounds this view in Romanticism and its emphasis on the process of speech production through which "sense" - the implicit, condensed, private, psychological associations made with a concept-becomes public and social and thus achieves meaning to the speaker. In this conceptualization of meaning, the focus is on the activity of speaking and its potential for enabling changes in consciousness. In essence, the expressive tradition focuses on the role of psychological processes in human development.

For the designative, the focus is on the finished, public word and the meaning that it suggests. The purpose of speech-both material written speech and ephemeral spoken speech-is thus to represent meaning in an artifactual form that allows for mediation by either the 
speaker or other people, with human development characterized by increasingly abstract concepts associated with words. For the expressive, the focus is on the process through which inner speech becomes public. The purpose of speech is thus to mediate the thinking of the speaker, with the artifactual form of the speech of only secondary importance. From a semiotic perspective, in an expressive conception, speech is a mediational tool that enables one to experience changes in consciousness through the articulation of fluid, condensed thinking in the form of the linguistic signs it produces. In a designative conception, speech is a sign that potentially can become a mediational tool through an interpretation of its codes.

Wertsch's (1996) distinction between the designative and expressive refers to broad philosophical arguments. In writing research the concern is more with the functions of writing, which is how I will refer to them in my application of these terms to composition theory. As noted, Murray and others have advocated the expressive function of writing as a vehicle for discovering meaning. In modern composition studies, this view received its impetus at the Anglo-American Conference at Dartmouth College in 1966 where James Britton (Britton, Burgess, Martin, McLeod, \& Rosen, 1975) advocated the "growth model," stressing the need for education to serve the psychological development of students through attention to learning processes. Moffett (1968) summarized the emphasis of the movement with his statement that "Rendering experience into words is the real business of school" (p. 114). Building on the foundation of both the Dartmouth conference and the movement toward attending to the process of writing initiated by Braddock, Lloyd-Jones, and Schoer (1963), Emig (1977) characterized writing as a "unique mode of learning" (p. 122) that educators should emphasize to cultivate students' thinking. Applebee (1981) similarly described writing "as a tool for exploring a subject" (p. 100), contrasting his view with traditional instruction that is teacher and product centered.

The growth model produced "writing to learn" pedagogies that have become, as Ackerman (1993) notes, "secure within the ideology of modern literacy instruction and research" (p. 335), providing the foundation for the instructional recommendations of the widely inserviced National Writing Project (Langer \& Applebee, 1987) and many Writing Across the Curriculum programs (e.g., Martin, 1984). These approaches typically advocate such modes as journal and free writing that allow students to use the process of writing to generate ideas (e.g., Emig's, 1971, advocacy of "reflexive" writing). 
Writing-to-learn emphases have typically been cast as process approaches to composition in contrast to those that emphasize attention to products. Yet a number of researchers have looked at written products as rich sources of meaning, lending a dynamic quality to the designative functions of writing that are denied in many arguments for expressive writing. From a semiotic perspective, signs are the bearers of meaning that structure cultural practices. Signs do not have autonomous meaning but rather take on meaning through their role in the cultural history of the people who produce and interpret them. The meaning of particular signs may change through the activities of the people who use them. For instance, the figure known as the swastika has emerged in a number of cultures, serving as a mystical symbol in indigenous North American tribes, India, Japan, Persia, and other countries and cultures. Prior to the rise of the Nazis, the swastika was a religious symbol in Western culture and is still often found in the artwork of old Christian churches. Following its adoption by Hitler, however, the swastika became widely interpreted as a symbol for genocide and terror. This cultural sign, therefore, rather than having a fixed, objective meaning, has been construed in different ways depending on the cultural experiences of the people who interpret it.

Writing researchers have similarly argued that written signs have latent meaning potential, both to the writers of the texts themselves and to other readers. Wells (1996), in describing the artifactual nature of written texts, maintains that "the primary function of writing is to mediate recall and reflection" (p. 2); that is, through committing thoughts to paper, a writer may return to them in their corporeal form and use them as the basis for further thinking. Individuals can thus create material signs that in turn mediate their own continued thinking.

Other researchers have focused on the relationship between writers and readers, a much more precarious relationship due to the possible lack of intersubjectivity between them. Because they bring different histories to their interpretation of linguistic signs, different readers may come away with readings of texts that are different from one another's as well as different from those initially intended by the speaker or writer, just as the modern skinhead and the Persian of antiquity would undoubtedly read different meanings into the swastika no matter what intentions the original inscriber had in mind. Similarly, as Rosenblatt (1978) would predict, linguistic signs are subject to multiple interpretations, as illustrated by the notably differ- 
ent interpretations of the same short story by case study students interpreting it through artistic and dramatic media (Smagorinsky \& Coppock, 1994, 1995a, 1995b).

Arguing in this vein, Nystrand (1986) states that "writing and reading are collaborative, social acts" (p. 47). Nystrand focuses on finished texts, which he argues "must strike a balance between the expressive needs of the writer and the comprehension needs of the reader" (p. 47). He refers to this relationship as the "reciprocity principle," which he states as follows: "In any collaborative activity the participants orient their actions on certain standards which are taken for granted as rules of conduct by the social group to which they belong" (p. 48, emphasis in original). Essentially, "good" writing is not writing that has inherent qualities that meet some external standards, as assumed in the formalist designative views criticized by Applebee (1981) and others, but instead is "in tune" with readers in terms of their shared expectations for tone, dialect, vocabulary, syntax, values, theme, and other traits. Good writers thus fashion texts that do not exclude particular intended readers. These texts can then serve as tools to mediate understanding among readers.

The designative and expressive traditions have provided a framework for viewing the process and product of writing as oppositions. Emig (1971), for instance, criticizes traditional school instruction as being "other-directed" and "other-centered," concluding that "too often, the other is a teacher, interested chiefly in a product he can criticize rather than in a process he can help initiate through imagination and sustain through empathy and support" (p. 97). Instead of accepting this dichotomy, I will attempt to establish some premises for viewing both the product and process of writing as complementary aspects of a semiotic, meaning-oriented view of composing.

To do so I will use data from a case study of one high school senior writing over a 4-month period. His writing experiences suggest that the activity of writing itself can be mediational when a writer values not only the tool of writing but the uses to which writing is put. Through this activity, writers can create a set of signs that serve a regulative function for both their own continued reflection and as a mediator for readers who are consonant with the codes of the text. A related finding of this research is that the focal student's experiences in the research process provided additional mediation of his thinking, primarily in terms of his unique uses of the protocol condition as a means of producing an artifact (his tape-recorded utterance) for contemplation, further illustrating the mediational potential of both the 
expressive and designative aspects of composing. The data from this case study illustrate the potential of both the expressive and designative functions of writing for enabling writers to develop new meaning and challenge the dichotomous thinking that characterizes many current debates in composition studies about the relative merits of process and product as focuses of attention.

\section{CONTEXT OF THE INVESTIGATION}

\section{The School}

The research took place in a large (1,400 students) 2-year senior high school in the American Southwest. The school was the only high school in a college town of more than 80,000 residents located about 20 miles from a large city. Most students and faculty were White, with the largest minority groups among the students being Native American and African American.

Instruction throughout the core academic departments tended to be traditional, that is, designed for the college bound student and reliant on teacher-dominated patterns of discourse. The five-paragraph essay was a staple of English department writing instruction, and literature was taught through teacher-led discussions outlining New Critical approaches to texts (see Marshall, Smagorinsky, \& Smith, 1995, for a detailed analysis of such discussion patterns). Teachers interviewed in the English department revealed that they believed learning the principles of New Criticism to be the most effective way of becoming a skilled reader. The community was conscious of standardized test scores as an indicator of school quality, and the high school reflected the community's interest in maintaining conventional indicators of quality.

\section{The Student}

Doug was a German American senior who would graduate at the semester break of his fourth year in high school due in part to his having earned course credit in summer school following his junior year. In the semester during which he produced his protocol, he took courses in British Literature, Creative Writing, Media Productions, 
Sewing, and Keyboarding II, and also received course credit for working as a library aide.

In many ways Doug was a typical middle-class American teenager. On an interest inventory he filled out at the beginning of the year for his British Literature class, he identified his favorite television shows as Doctor, Doctor, The Simpsons, and Roseanne; his favorite movie stars as Leslie Nielsen and Weird Al Yankovic; his favorite literary character as Holden Caulfield (although he revealed that he "hated" the frequent profanity); and his favorite magazines as Time, Newsweek, Baseball Card Monthly, and Mad. He concluded the inventory by saying, "I HATE homework. I want to live in Pennsylvania. I am goofy." As were many of his classmates, he was a devout Christian who participated actively in church functions.

Doug was also unique in many ways. In participating in this research, Doug carried around a portable cassette tape recorder for 4 months and thought aloud as he composed, revised, or considered his writing. Volunteering for this research and then following through conscientiously with the responsibility distinguished Doug from most classmates; 8 out of the original 10 volunteers for this study provided no think-aloud data. The one other student who did provide thinkaloud data provided no supplementary data such as a folder of collected writing. Doug, on the other hand, saved virtually all of his writing (including drafts) and provided 68 pages of think-aloud protocols plus the transcript from one writing conference with his British Literature teacher. (See Rosenthal \& Rosnow, 1975, for an extended discussion of the characteristics of volunteer research participants.)

Doug's experiences with writing prior to his senior year were in accordance with the prevailing instructional practices of the English department. Before his senior year Doug had not written extensively, nor had he particularly enjoyed writing. On his interest inventory he listed English among his least favorite school subjects and mentioned an occasion when he'd had "trouble" with a previous English teacher because they "didn't agree." In his reflective thinking on his protocol he said that "Before this writing workshop, I didn't ever write [poems]. I can't say that, I have wrote them, but I never liked to write them." Most of Doug's writing for school in the past consisted of writing some variation of the five-paragraph essay. Doug's writing prior to his senior year was concrete and form driven. In his recollection of prior writing experiences, he reported neither enjoyment nor learning being associated with the process of writing. 
Doug revealed in his follow-up interview that his sense of trust was a key element in his willingness to share his writing with others. Doug valued "third-party" listeners with whom he could share his thoughts without fear of betrayal, and his trust of his teachers and of me as researcher enabled him to employ the tools of writing and thinking aloud in important mediational ways during the course of the research. Doug's church upbringing, coupled with experiences of betrayal, increased the value he put on trust. He said during the followup interview that his close friends since late elementary school had all been girls: "I can open up a lot and discuss a lot of things with them. I know I have never been even close to being in a friendship with a guy who I could express those same things with." He reported that his distrust of male friends originated in elementary school when his closest friend abandoned him for some new friends, leaving him hurt and feeling emotionally forsaken. This same pattern occurred on two other occasions: A male friend "would get along with someone else and just kind of drop me."

Doug's emotional sensitivity distinguished him from other boys his age. He was one of the few males in his sewing class, for which he produced three teddy bears and a pair of boxer shorts. Home economics was a rare choice for a boy in Doug's sports-oriented Southwestern community in which the high school football coach (a part-time teacher) was paid substantially more money than the principal. Doug's choice of writing topics often revealed a need to explore his relationships with loved ones, particularly family members and girlfriends.

\section{The Classrooms}

Doug's senior year English classes provided a contrast to his previous experiences in school. The British Literature teacher, Ms. McDonald, was in her late 20s. At the time of the data collection she was in her fifth year of teaching and was working on a master's degree in English Education at a large state university. She had been a participant in a summer institute of the state affiliate of the National Writing Project 1 year before the data collection and had conducted several Writing Project in-services for schools in her region during the subsequent school year on the topic of writing conferences. She was active in her state National Council of Teachers of English (NCTE) affiliate and had been accepted onto the program of a regional NCTE conference for a presentation based on the in-service workshop she 
had developed through the Writing Project summer institute. These professional activities influenced her to adopt a different approach to teaching than that of most of her colleagues.

Ms. McDonald had received permission from her supervising administrator to divide each marking period (two per semester) into two $4 \frac{1}{2}$-week units. The first unit was devoted to the study of literature but departed from the customary chronological survey of British Literature, instead centering on thematic literature units that included multicultural material outside the traditional British canon. The literature units stressed the personal growth of students through both the content of the literature studied and the processes emphasized by Ms. McDonald through her teaching.

She began the year by teaching students how to keep response logs, explicitly scaffolding their learning by leading them through a series of activities designed to acquaint them with the genre and then give them guided practice in the processes, a sequence she attributed to her understanding of Hillocks's (1986) account of "environmental" instruction. She first provided models of reading logs and then talked about how she kept them for herself, writing down key words and phrases on one side of a ledger and using the other side to record thoughts and feelings in response. She then gave them small group practice in responding to an accessible poem based on the theme of identity, which would be the focus of the literature unit that would follow. Students worked in small groups discussing how to respond to the poems and producing a sample response collaboratively. Ms. McDonald followed this activity with a whole-class discussion in which each group read their responses and both she and the students provided feedback, discouraging summary of passages and encouraging questions about the text, affective responses, and personal reflection in relation to the content of the passages. For homework, she assigned them a new passage and told them to produce a reading log response, which she then reviewed in class the next day and critiqued in a similar manner.

Through this process, Ms. McDonald established her own value on personal response to literature, on affective writing, and on the development of personal criteria for evaluating literature. These processes were reinforced by the content of the literature studied in the unit, primarily poems in which the authors reflected on personal experiences and how they had shaped their identity. Ms. McDonald told students of her own interest in personal writing, particularly with regard to exploring the ordinary events of her life and the truths they 
revealed, and frequently referred to her own such writing. Through her deliberate instruction in reflective, identity-centered writing, Ms. McDonald established her values for schooling and for literature and composition studies in particular.

The problem-solving environment she provided for Doug and the other students was different from the New Critical emphasis of his prior English classes. Rather than establishing literary signs as having an objective meaning available through an understanding of New Critical codes and interpretive conventions, Ms. McDonald emphasized that students' attribution of personal codes to literary signs was paramount to their development as readers and that their response logs were paramount to their development as readers and writers.

This emphasis on personal exploration carried over to the writing workshop, in which students were encouraged to write in genres of their choice, develop a personal voice, and use their personal experiences and interests as the basis for their content choices. Ms. McDonald would provide minilessons on particular topics at the beginning of each class and would spend the rest of class either writing along with students or conducting conferences with them. Often these minilessons served to make students aware of conventional constraints; she often geared these lessons toward the expectations of different audiences, with particular attention to academic expectations for college-bound students. Students were then responsible for using the writing time to pursue their own projects with their own audiences in mind.

Ms. Stephenson, the Creative Writing teacher, was in her mid-40s, had earned a master's degree in English literature, and had been a participant in a summer institute of the state affiliate of the National Writing Project. She had also been awarded a grant to participate in a prestigious institute for teachers of writing that was, as she described it, "a weekend retreat primarily for teachers to bring back [to the classroom] materials and techniques and crafts using writing" and to work on their own creative writing.

Ms. Stephenson said that her own experiences as a writer had strongly influenced her teaching of Creative Writing: "I think that as a teacher of writing that kids need to realize that I write drafts, and that first drafts are not very good. Sometimes it may take 12 times to get a poem even to be of passing interest or a passing draft." Ms. Stephenson regarded writing as an extended process during which the content and form of a piece were developed. Her classes reflected this recognition of the exploratory nature of writing, with students 
given opportunities to work on their compositions over extended periods of time.

Much of class time was spent on writing: "My theory is that writers write, and so we just really get down to business in here. I don't talk a lot in here. I think the way you learn to write is to actually do something." One of Ms. Stephenson's primary goals was for each student to "have learned something more about himself or herself. If that is the only outcome, then I am glad, because I think that through discovery, using literature as a base, then people can understand themselves better." Ms. Stephenson hoped for students to feel better about themselves as students and as writers. Virtually all of the feedback students got from Ms. Stephenson consisted of encouragement rather than critical response. Her class, she said,

is a place for students to experiment and to get confidence and to let go. ... The kind of writing in here to me is beautiful because these people have been in classes all day, that is the plus of the way the classes are structured. So when they come to my class, they feel comfortable. They make themselves right at home. I feel that we are friends.... I would like for it to be a bond of trust, and I think we have a mutual trust.

Ms. Stephenson sought to build on the trust that she developed and have students be honest with one another both in their conversation and in their writing, saying that

I think, more than anything, that we have tried to put away our masks in here. ... I encourage them so that their folder will be worth something to them at the end of the semester, that they be honest, and write with feeling, and write about things that have some sort of significance to them. If something is not of significance, then it is not worth writing about.

Both classes, then, emphasized writing as a medium for exploration of personal issues through any genre that enabled students to learn. Both teachers sought to establish an environment of trust, with students working toward finding a personal voice to develop and express their ideas and feelings. Both classes allowed a great deal of time for writing, with Ms. McDonald providing more specific instruction in how to write according to specific conventions. Overall, both classes emphasized the expressive functions of writing, with writing encouraged as a tool for mediating students' reflection on their per- 
sonal experiences. Ms. McDonald also attended to the designative functions of writing, with the literature they read seen as a sign system that students could use as a tool for personal reflection and personal meaning construction, and their writing seen as needing to adhere to particular conventions. She and her students attended to social practices such as following the formalities of academic writing and poetic styles to help students prepare final versions for their ultimate readerships. Ms. Stephenson's primary emphasis was on students' personal growth, although as sponsor of the school's literary magazine she also encouraged them to submit their strongest pieces for publication and thus attended on some occasions to the final form of their writing.

\section{Doug's Writing}

Doug's folder of collected writing included writing from three classes. For British Literature/Writing Workshop he produced a number of different types of writing. The first composition in his folder was an essay on how four different people (his best friend, mother, teachers, and himself) perceived him, a piece that had been initiated by a worksheet that required him to draw a picture of each of the four perceptions (i.e., his mother saw him as a vacuum cleaner that sucked up money). Doug also wrote two essays based on activities from Observing and Writing (Hillocks, 1975). The first was an essay in which he made inferences about the personality and mission of a spy based on an examination of the contents of the spy's pockets. The second blended Hillocks's observational activities with an assignment from Kirby and Liner's Inside/Out (1988) and required a character analysis. Doug wrote about a man he had observed drinking coffee in a fast food restaurant, a composition he had produced on a class excursion to a restaurant next door to the school during a class period. His other formal pieces included a satiric drama about the hypocrisy of a church congregation and their intolerance toward a new, recently divorced preacher; a sequel to "Casey at the Bat" entitled "Casey Bats Again"; a poem about his grandmother in Pennsylvania; and a poem about a romantic experience that he had also turned in to his Creative Writing teacher.

In addition, Doug responded to an interest inventory in which he wrote about his hobbies, affections, and activities. He also kept a reading log. He was then required to develop an argument from his reading log ideas, using the claim-data-warrant argumentative struc- 
ture outlined in Kahn, Walter, and Johannessen's (1984) Writing about Literature. Doug also wrote a final exam that included true/false and matching items on the literature and vocabulary from the semester, questions asking the significance of specific quotes from the literature, a brief argument supporting one of two given claims about Richard Wright's short story "The Man Who Was Almost a Man," an essay (incorporating the claim-data-warrant structure and additionally evaluated on spelling and mechanics) in response to one of three given questions, and an extra credit item in which he could express a significant idea he had developed while studying for the test that he had not written about elsewhere in the exam.

For Creative Writing, Doug wrote six poems on various topics, including his love life and the subject of poetry itself; a brief play about the breakup of a relationship; two brief personal experience anecdotes; a story based on an experience of a couple he knew in which the man had broken the woman's nose while trying to put his arm around her in a movie theater; a brief essay about his experience visiting senior citizens in a nursing home; a brief short story about a father and son; a number of "starter exercises" that his teacher had used to stimulate his writing; an essay about what he would do if he were in charge of the school; and a reading log.

For Media Productions Doug wrote a marketing proposal in which he and some collaborators developed a perfume called Uncontrolable [sic] and identified its target audience. He also collaborated on two interviews for documentary films, one with Doug as the subject and one with another student as the subject. The text for the interview conducted by Doug included details of how each segment would be shot by the camera (e.g., close-up, medium shot, over shoulder). The text for the interview with Doug as subject was a handwritten rough draft; Doug did not save the final version that would have included the camera angles.

\section{METHOD}

\section{Data Collection}

Data were collected in five related sets: situated protocols, classroom observations and teacher interviews based on those observations, a collection of Doug's writing from several courses during the 
semester, an interview with Doug at the end of his semester of participation stimulated by his collected writing, and a follow-up interview conducted 3 years after the data collection.

The situated protocols were designed to gain insight into Doug's composing process. He was issued a portable tape recorder and a set of tapes and asked to think aloud whenever it was feasible during the second marking period of the first semester of his senior year in high school. He was paid $\$ 10$ for each tape he filled. He was encouraged to think aloud at home, in the library, in school, or wherever else he might be when writing for school or for other purposes. The intention of having the writer think aloud in situ was to try to locate the methodology in the times and spaces in which Doug ordinarily wrote and thus capture his real-time composing process to the greatest extent possible.

Doug's British Literature/Writing Workshop class was uniquely situated for such a study. At the back of the classroom were two enclosed conference rooms where Doug could think aloud without disturbing the writing of his classmates. Furthermore, because the structure of the class was a Writing Workshop (modeled after Atwell, 1987) in which students could write on any topic of their choice, the opportunity existed to capture Doug in the process of composing many different types of texts.

\section{Data Analysis}

The data were analyzed in a seminar for eight doctoral students who were finishing their course work and preparing for their general examinations and dissertations. The course was designed to give them experience in data analysis prior to collecting and analyzing their own data.

The primary source of data was the situated protocols. Other data sources helped to provide contextual information about the classroom and provided triangulation for unclear points in the protocol analysis (e.g., an analysis of Doug's collected writing helped to determine the accuracy of the transcript of his think-aloud composing, or to determine whether he had written a specific piece for British Literature/ Writing Workshop or Creative Writing).

The protocol analysis was conducted over a period of 12 weeks. The analysis began with a preliminary reading of Doug's think-aloud protocol (consisting of 68 pages divided into 1,270 segments), the interview transcripts, and his collected writing. The group discussions 
of the data led to initial insights regarding the general patterns found across the data and the development of possible coding categories emerging from a semiotic perspective on composing. The research team then developed and applied a prototype coding system to the entire protocol and refined the categories over a 9-week period. After agreeing on a final coding system, we then discussed possible ways to proceed with the final coding of the transcript. Conventionally, think-aloud protocols are analyzed by separate coders and their decisions are compared to come up with a reliability rating. In this study, we decided that it was more consistent with the theoretical underpinnings of the investigation to make all decisions through discussion and mutual agreement. The final coding decisions, therefore, were determined through a final group reading of the protocol transcript and a consensus of the group on the specific code for each segment in the transcript.

We developed the coding system based on concepts emerging from theory and research grounded in social constructivist approaches to semiotics. Ultimately, the coding attempted to identify Doug's attention to the designative and expressive functions of writing and the specific ways in which he drew on both.

The coding system consists of three levels of codes. Level I codes describe the general stance Doug took during the protocol. At times, he provided a conventional think-aloud, at other times he would take out previously written pieces and either revise them or talk about them. These distinctions are made through the Level I codes.

Level II codes describe the purposes, concerns, and sources of Doug's writing decisions. Level II codes fell under two general areas. The first area is the writing's Designative Function, which concerned the way in which the codes of his written text would be understood by his readers. The second area is the writing's Expressive Function, which concerned the way in which his writing and his experience with the think-aloud procedure mediated his own development with little or no concern for how the codes of the resultant text would be read. As will be noted in the data analysis, the two categories were not mutually exclusive; that is, the designative and expressive functions did not represent the oppositions that characterize the debates outlined previously. Often statements coded as expressive led to the production of signs that in turn Doug used as tools for his continued construction of meaning.

Level III codes described Doug's sense of readership, at some times focusing on Doug's concern for readers of his own text, at other times 


\section{Table 1}

Frequency of Protocol Categories

Revision: Revision:

Generation In Progress Retrospective Reflection Total

\begin{tabular}{|c|c|c|c|c|c|}
\hline \multicolumn{6}{|l|}{$\begin{array}{l}\text { Designative function } \\
\text { Recrirocal relationships }\end{array}$} \\
\hline Readers of Doug & 2 & 0 & 1 & 19 & 22 \\
\hline Doug as reader of others & 0 & 0 & 0 & 9 & 9 \\
\hline Doug as reader of himself & 0 & 0 & 0 & 2 & 2 \\
\hline \multicolumn{6}{|l|}{ Sensory effect (SE) } \\
\hline Readers of Doug & 2 & 0 & 1 & 13 & 16 \\
\hline Doug as reader of others & 0 & 0 & 0 & 0 & 0 \\
\hline $\begin{array}{l}\text { Doug as reader of himself } \\
\text { Emotional effect (EE) }\end{array}$ & 0 & 2 & 0 & 9 & 11 \\
\hline Readers of Doug & 2 & 0 & 8 & 5 & 15 \\
\hline Doug as reader of others & 0 & 0 & 0 & 7 & 7 \\
\hline Doug as reader of himself & 2 & 0 & 0 & 2 & 4 \\
\hline \multicolumn{6}{|l|}{ Thematic effect (TE) } \\
\hline Readers of Doug & 0 & 0 & 0 & 4 & 4 \\
\hline Doug as reader of others & 0 & 0 & 0 & 6 & 6 \\
\hline Doug as reader of himself & 0 & 0 & 0 & 0 & 0 \\
\hline \multicolumn{6}{|l|}{ Appropriateness (A) } \\
\hline Readers of Doug & 2 & 0 & 0 & 0 & 2 \\
\hline Doug as reader of others & 0 & 0 & 0 & 4 & 4 \\
\hline Doug as reader of himself & 0 & 0 & 0 & 0 & 0 \\
\hline \multicolumn{6}{|l|}{ Validity (V) } \\
\hline Readers of Doug & 0 & 0 & 0 & 4 & 4 \\
\hline Doug as reader of others & 0 & 0 & 0 & 0 & 0 \\
\hline Doug as reader of himself & 1 & 0 & 4 & 0 & 2 \\
\hline \multirow{2}{*}{\multicolumn{6}{|c|}{$\begin{array}{l}\text { Formal considerations } \\
\text { Intertextual appropriations (IA) }\end{array}$}} \\
\hline & & & & & \\
\hline Readers of Doug & 0 & 0 & 0 & 0 & 0 \\
\hline Doug as reader of others & 33 & 1 & 3 & 57 & 94 \\
\hline Doug as reader of himself & 0 & 0 & 54 & 62 & 106 \\
\hline \multicolumn{6}{|l|}{ Form (F) } \\
\hline Readers of Doug & 0 & 0 & 4 & 2 & 6 \\
\hline Doug as reader of others & 0 & 0 & 0 & 0 & 0 \\
\hline Doug as reader of himself & 27 & 8 & 112 & 9 & 129 \\
\hline \multicolumn{6}{|l|}{ Rhetorical effect (RE) } \\
\hline Readers of Doug & 2 & 0 & 0 & 5 & 7 \\
\hline Doug as reader of others & 4 & 0 & 0 & 0 & 4 \\
\hline Doug as reader of himself & 15 & 2 & 0 & 0 & 17 \\
\hline \multicolumn{6}{|c|}{ Questions of authority (QA) } \\
\hline Readers of Doug & 0 & 0 & 11 & 15 & 26 \\
\hline Doug as reader of others & 0 & 0 & 0 & 0 & 0 \\
\hline Doug as reader of himself & 0 & 0 & 0 & 0 & 0 \\
\hline
\end{tabular}


Table 1 Continued

Revision: Revision:

Generation In Progress Retrospective Reflection Total

\begin{tabular}{|c|c|c|c|c|c|}
\hline \multicolumn{6}{|l|}{ Expressive function } \\
\hline \multicolumn{6}{|l|}{ Expressive uses of writing } \\
\hline Emotional mediation (EM) & 3 & 0 & 0 & 47 & 50 \\
\hline Writing as epiphany (WE) & 0 & 0 & 0 & 21 & 21 \\
\hline Feeling of authority (FA) & 0 & 0 & 0 & 12 & 12 \\
\hline \multicolumn{6}{|l|}{$\begin{array}{l}\text { Expressive uses of the } \\
\text { research process }\end{array}$} \\
\hline Think-aloud as tool (TAT) & 2 & 0 & 18 & 84 & 104 \\
\hline \multicolumn{6}{|l|}{ Other } \\
\hline Reread text (RT) & 68 & 2 & 162 & 223 & 455 \\
\hline Positive judgment (PJ) & 10 & 1 & 31 & 7 & 49 \\
\hline Incidental (I) & 1 & 1 & 12 & 10 & 24 \\
\hline Negative judgment (NJ) & 0 & 0 & 1 & 7 & 7 \\
\hline \multicolumn{6}{|l|}{ Total } \\
\hline All categories & 176 & 17 & 432 & 645 & 1,270 \\
\hline
\end{tabular}

focusing on his reading of other writers' texts, and finally on his own reading of his own writing.

Each segment in the protocol received Level I and Level II codes; those Level II segments representing the Designative Function received a Level III code. In addition, we developed a category of "other" to designate segments that involved rereading his text, making a brief judgment about it, or making a comment incidental to his writing (see the appendix for definitions and examples from the transcripts, and Table 1 for the frequencies of each category). The subcategories beneath each heading are listed in order of frequency.

\section{RESULTS}

The report of the protocol results will follow the general outline of the coding system. The following sections discuss Doug's designative and expressive uses of writing. The protocol data are presented in conjunction with validating data from the interviews conducted with Doug. 


\section{Designative Function}

Segments coded as having a designative function described occasions when Doug would refer to the manner in which a written text would provide a set of signs that could potentially serve as a blueprint for constructing meaning. These segments fell into two areas. The first is the reciprocal relationships established between a writer and reader in terms of their intersubjective understandings, that is, the degree to which a reader and writer are in tune in terms of a text's images, emotional message, themes, appropriateness, and validity. The second is the formal considerations a writer would make in producing a text, including the structure of its narrative content, the stylistic conventions it follows, the rhetorical effect it might have on readers, and the location of authority in making decisions about formal aspects of writing. The sections that follow illustrate how Doug drew on writers he admired for worthy models and how he then integrated the traits he appreciated most in their writing into his own.

\section{Reciprocal Relationships}

Doug's need to connect with and affect his readers motivated many of his decisions as a writer. Frequently, his understanding of how to craft his writing to be in tune with his readers came from his own reading of his favorite writers (coded at Level III as Doug as Reader of Others). He singled out Garth Brooks, the country and western singer, as particularly influential on his writing. Brooks was a native of a nearby town and received extensive play on the local radio stations, allowing Doug great familiarity with his work. When asked about his affinity for Brooks in the follow-up interview, Doug said, "His words, his songs that he sings, when I look at the words, it just like smacks me in the face sometimes, of wow, this is really true.... You don't have to do any deep thinking about this symbolization he has made. It is there, and it is just amazing." Doug admired Brooks's ability to communicate directly with an audience, to allow readers to connect with his images and themes:

I can definitely see situations that he is talking about and then put them right back on me. He had a song called "Unanswered Prayers." In the chorus, "Some of God's greatest gifts are unanswered prayers." How many times have I prayed for something and I haven't gotten it, and now I look back and think He knew what He was doing. It is situations 
like that where the things he talks about in those songs are so easy to relate back to me in my life.

Among Doug's goals as a writer was to affect readers in the same way he was affected by those he admired. He made a deliberate effort to identify writing that he found engaging and incorporate elements of that writing into his own. He explained during a retrospective part of his protocol that

I can't read anything that is not funny or amusing. So why should I write something I can't read? And that is something I personally feel very strong about. Because there are so many stories that I have read that, you know, it is one of those things where you read a paragraph and you have to go back and read it again, because you don't even remember any of it, it was so boring. And I just don't understand what kind of state of mind the author is in when they are writing that. I mean maybe it was exciting or interesting to them, but you know, I want to be able to write a story where people can read it through once and absolutely love it, have fun with it, and understand it.

In the protocol, Doug went on to read the lyrics to a Garth Brooks song called "The River," which he admired because "everyone can relate to this song. It is talking about life. It is talking about taking chances. Everybody can relate to it. That is almost a personal goal of mine. I want people to be able to relate to my works." To Doug, Garth Brooks's ability to create a thematic effect with which his listeners could relate made him a writer to emulate.

With such writers as Brooks serving as exemplars, Doug in turn tried to move his readers emotionally. On one occasion during the protocol, he said, "I actually made a girl in my creative writing class cry when she read that [poem] and you know, it felt good. It was such a neat feeling to know that something I wrote, something that I just wrote down on paper made someone cry." Just as Garth Brooks moved Doug, Doug sought to move his readers. Following his completion of "Casey Bats Again," he reread the poem and said as part of his protocol,

I would like to have the guy who read "Casey at the Bat" [on a recording] read mine. I wonder how it would sound. I could probably do a pretty good impression of him. I tried to get a little bit dramatic as I read, but you know I just couldn't do it. Maybe at home I can do it better. Uh, I have read it for, a teacher conference on this would probably 
help me, see what she thinks about it. I don't really like this. I have to be truthful, I really, really like this. I think I accomplished what I had in mind with this poem and that was to create an atmosphere just like the guy that wrote "Casey at the Bat." Try to create the excitement... After I wrote it and went back and read it back to you, even for me, I grew excited. I knew he was going to hit it out, but I was getting excited. Someone that has even read the story can still get excited about it and that is the way it is with the original one.

This sense of excitement derived from the emotional effect that the poem had on Doug as a reader of his own work. This excitement, he assumed, would be experienced by readers of his poem, just as reading the original "Casey at the Bat" had affected him.

Doug also was conscious of the importance of having his readers share the experiences he was trying to create through their sensory response to his writing. For Creative Writing, Doug and his classmates were given an assignment to write "a poem that was supposed to describe a journey or a trip." Doug's poem was eventually published in the school literary anthology. In his journey poem he labored to create images that would enable a reader to enter the work he was creating: "And I think that is a pretty good quality, quality is the word I am looking for. The good quality, to be able to write so little, but yet make it seem such a long time. Because I want them to picture hours of walking through this tunnel, but I am not going to write fifty pages to depict hours of walking through the tunnel."

Doug wanted to convey to his readership the experience of the activity of the primary character in the poem. To do so he needed to craft images that created a sensory effect on his readers:

You actually think, this guy is killing a dragon. I mean when I read that, I actually feel, I can hear him talking. I can hear him yelling. It was "without the dragon dropped." I don't know, when I read this I don't get an image of a dragon dropping or anything. I maybe, maybe I want to revise this to where I give a little more description you know. Instead of saying "without the dragon dropped, still burning to the ground and the fury truly was gone," maybe I want to say, "the dragon twists and turns, fire is leaping from its body, pain and anguish surround him." I don't know, something like that. I think I want a little bit more description of the dragon dropping to the ground.

Throughout the protocol, Doug revealed a concern with establishing a relationship with his readers based on their shared understanding 
of the affective qualities of his writing. His production of and reflection on these texts illustrates Nystrand's (1986) claim that "pieces of writing do not function communicatively at the time of their creation; they only bear a potential for communication. Learning to write is precisely learning to create such a potential" (p. 102). Doug's efforts to create a potential for meaning through the designative functions of writing revealed his efforts to establish reciprocity with his writers.

\section{Formal Considerations}

In addition to his efforts to create an affective relationship with his readers, Doug showed an awareness of formal conventions, particularly during his revision of "Casey Bats Again." The poem required Doug to constrain his writing by producing identically metered couplets that fit a standard stanza length, and Doug therefore spent most of his time during revision finding words with the proper number of syllables, finding words that rhymed, avoiding repetition of words, and making other changes to the sentence-level form of the poem. The following example from his on-line production (coded Generation at Level I) is typical:

Needs to be a little bit of something in that third line. Cate didn't make it to second before he tripped. It would be real smooth if I could say he, before he tripped along the way. I would have to change the rhyming scheme. OK, I can do that. Cate didn't make it to second before he tripped along the way, and wouldn't have made it if his life depended on it anyway. And he wouldn't have made it there and wouldn't have made it there if his life depended on it anyway. No, think I will leave it as it is. Cate didn't make it to second before he, I can say along the way he tripped on the. Cate didn't make it to second for along the way he tripped and wouldn't have made it anyway if his life depended on it. Yes, that is good.

Doug frequently focused on form during his revision of pieces, with a total of 135 segments coded at Level II as form statements. One possible explanation is that his "teacher edits" in British Literature/ Writing Workshop stressed mechanics and so he worked on revision for the purpose of smoothing out surface features. In addition, although both teachers stressed writing for personal growth, both also required finished products, which called attention to the need for polished prose. Another contributing factor was Doug's own desire 
to have the form of his writing be "correct," at times so that a piece met the generic requirements that he had chosen (as in his effort to make "Casey Bats Again" match the structure of "Casey at the Bat") and at times because he wanted his finished products to appeal to his readers as much as possible.

In his protocol Doug frequently appropriated prior texts to generate new written texts; that is, he situated his writing in an intertext. At times these prior texts were written, but they also came from film, conventional language, narratives from his own experiences, narrative texts from the experiences of friends, and other sources. Doug's narrative productions were often deliberately based on prior texts that he had seen, read, heard, or otherwise experienced. For instance, one of the pieces he wrote was a re-creation of an experience related to him by two people of his acquaintance. He said during a reflective section of his protocol that "We had to write a paper about something bad or something terrible had happened on a date." He then explained how he had taken a story about his friends' experience and created a narrative out of it. In the original experience,

These two people from my church, one is a youth leader now and she is married to another guy and has a daughter. The other one is still single and we rag him about that. They went to high school here together about 12 years ago. Twelve? Yeah, I'm being generous about that, somewhere around there and they dated each other and they went to the movie one time and David was the guy and Kris was the girl and he went to put his arm around her and he elbowed her right in the nose and broke her nose in the movie theater. And this was just so funny to me, so I had to write about that and I was laughing the whole time through, because every time I talk about it or write about it, I picture this happening and God that must have been funny. He must have been terrified when it happened. But just thinking back on it, I mean I would have given anything to have seen that. I am writing this out of memory of what they told me and adding a bit of a story line to it.

As the grist for his story, Doug drew on a prior oral text related to him by friends from church. His "adding a bit of a story line" included several innovations. For instance, he said that "I don't know how far into dating they were when this happened but I tried to make this real dramatic and sophisticated date where David is trying to do everything perfect. So that no one would have any idea that the surprise ending would happen." These last two statements were coded as 
being written for rhetorical effect; Doug's desire to make the broken nose work dramatically led him to set up the ending by re-creating the date as an otherwise exquisite experience. As Doug said, "I don't know if this ever happened. But it is making a true story into a 'story' story you know. It is making something real to me fictional."

Doug's effort to create a dramatic rhetorical effect led him to create emotional swings in his narrative. To do so he drew on the text of a comedy sketch he'd seen on television:

I don't know if you have ever seen the Saturday Night Live, Steve Martin plays a midget, well you don't know that. He and this lady are at a table eating and they are describing each other to themselves and as they say something that the other person finds attractive or a plus in their personality you hear this whistle go up like-I can't whistle, I am sorry-it goes up and he will say something to contradict it and it will go down and it is like him saying, "I have a condo on the beach" and this whistle goes up in her mind and says, "Yeah, my mother lives with $\mathrm{me}^{\prime \prime}$ and it goes down. And I kind of have this in mind, when I was writing this you know, [reads from his narrative] "The moment of truth arrived and he went in one swift motion," and that whistle goes up and [reads] "right into Kris's nose" the whistle goes down, [reads] "He broke her nose. He just ruined the perfect date."

For the narrative on the date gone awry, Doug explicitly drew on two texts-the oral text from his friends' experience and the visual text from the television script-to create his own original text. Doug additionally drew on story scripts he knew from various experiences to provide the plot structure for other writing from the semester. In writing a poem based on medieval images, he reported that at one point in the narrative he (as narrator) was trapped by fire from a dragon's mouth, and "I had to find my way out. I couldn't die. It sucks when the hero dies. I couldn't die." This appropriation of heroic plot structures provided the material for a resolution to the dilemma faced by the narrator, one that he solved by summoning a mythic sorcerer named Merlin who orders the dragon to desist.

His production of this poem also required another type of intertextual appropriation, that being his borrowing of conventions for meter in modern poetry. When asked during his interview how he had learned how to adapt his choice of rhythm and meter for this poem, as opposed to the strict conventions he followed for writing his epic sequel "Casey Bats Again," he said, 
I think a lot of it comes from reading poetry. We studied some of the English poems in summer school. I would read them. At first it was kind of difficult to write my own poetry with [that form] because I wanted to start my rhythm and my voice over when it gets to a new line. I had to learn to block that out because it wouldn't flow real smoothly. So I just started writing and whenever I got done with a short thought, I would start a new line. I had to make a conscious block in my mind to stop trying to get into a certain rhythm.

Throughout his protocol, Doug would draw on prior texts from his experience for the themes, form, and scripts of his own texts. He consciously produced writing that fell into genres with which he was familiar, appropriating their conventions to provide the structure, themes, content, images, and tone of his own writing.

Just as Doug drew on the personal history of his friends from church to create his narrative about a bad experience on a date, he frequently appropriated narrative texts from his own experience to provide the content for his writing. For creative writing, for instance, the teacher asked the students

to take a place from a long time ago and think about how we thought of it then. Concrete details, and then we had to think about that place now and how it feels. So I thought about my grandma's house and I remember it was huge. I can always remember the smells from the kitchen and my grandpa. Not the smells from my grandpa, but smells from the kitchen, my grandpa, the wavy hills that go towards the house, the woods beside it, the sandbox, and the gravel driveway and the baseball with my grandpa and the basement I thought was really scary, old and musty. Now this house seems kind of small, but smells still come from the kitchen, a huge yard that I never really thought about before, the porch swing, I never really took the time to enjoy. I now consider it my home.

In this segment of retrospective protocol, most statements were coded as "personal," with Doug reading the text of his own experience. He then appropriated that experience to create a new narrative, one that he said had a great emotional effect on his reader: "That's how I said that it hit her in the heart. Ouch. Kind of makes me feel good that I can do that. You know you are a good writer if your writing hits home with a lot of people."

On the advice of his teacher, Doug revised part of this narrative by comparing his original feelings about his grandparents' house to his 
current feelings: "So what I did is, I went through and numbered off all of my details in the first paragraph and through the whole poem and then I would take them and write if it was from what I remembered before, I would write what I think of them now and if it was from what I think of them now, I would take them and write what I thought of them then." Doug's first draft thus served as the text from which he developed his revision, providing a text that he appropriated for his continued development of his narrative.

Doug invested much time on the designative function of writing, working to affect his readers in the same way that he found himself moved by his favorite writers. His designative choices revealed a strong effort to establish a reciprocal relationship with his readersidealized so that they resembled Doug himself in their expectationsso that they could relate to the themes he presented through simple, vivid, conventionally appropriate language.

\section{Expressive Function}

Doug produced much of his writing with a readership in mind and the reciprocity he needed to establish with his readers constrained and affected the ways in which he wrote. On other occasions, Doug revealed that he produced a text to explore his thoughts, emphasizing, as Langer and Applebee (1987) say, "the active role of the writer, who must organize and reformulate ideas and experiences in the process of writing about them" (pp. 6-7). Doug experienced this expressive function of composing both through his production of written texts and through his participation in the research process.

\section{Expressive Uses of Writing}

The section on the designative functions of writing outlines how Doug revealed his concern with the meaning potential of his finished texts. On some occasions, however, he wrote purely as a means of exploring his emotions. Such writing was not intended for others, only for Doug. Writing of this type received a code of Emotional Mediation in the protocol analysis. As Doug said on one such occasion, "I wrote [that piece] without stopping, it is what I felt at the moment. Luckily, I am not in those moods too often, but that was the way I felt right then and I had to put it down." Similarly, when Ms. McDonald asked for a freewrite on what a good writer does, he said, "Writing is the 
only way I can really express my feelings." For Doug, writing in response to such emotional needs served an immediate purpose:

I think I am kind of different because I have a lot of trouble revising in English and other writing classes where I have to write essays or something. Whenever I write, I just write and if I see something that is wrong with it, I will go back and change it. But once I am done with it, I am satisfied with it and I can't go back and change it because I think it is losing the meaning of what I wanted it to be and what I want it to be is me writing right then and not me going back and changing it two days later. I want what I write down to be fresh off of my mind and not a compilation of two different days' thoughts. ... I do think that my letters do reflect the way I write though because I go with the flow of my mind. I don't stop writing because I think that it takes away from what I really am.

The qualities that he referred to in this excerpt from his retrospective protocol are characteristic of writing that he called "letters" or "poems." When Ms. Stephenson asked her students to do a freewrite on how they viewed poetry, Doug said, "Poems are a difficult thing to criticize and in my opinion a poem should appeal to the writer and not necessarily the reader. Poetry in a way is not like any other genre. It is an expression of the writer and what they feel at the time it is written."

Doug's notion of a "poem" as a genre appeared to refer to its purpose, rather than its form. His lengthy piece "Casey Bats Again," for instance, was written in couplets and verses yet was by far his most meticulous and heavily revised writing of the semester; other pieces of prose, however, appeared to fit his criteria for poems.

Most of Doug's use of writing for emotional mediation came in short, discrete pieces that he might or might not turn in to his teacher, and in which another person's response to the form of the written product was of negligible importance. At times, however, Doug revealed that he shared both concerns simultaneously. As he prepared to write the ending of "Casey Bats Again," Doug said,

You know to tell you the truth, I don't even know how I am going to end this poem. I am getting to where Casey is at the bat, the count is one and one. There would only be a few more pitches and I still don't know whether I am going to have him strike out again or hit a home run. I only know when I get to that point. I will know if it is going to go to the 3-2 count. If it is going to be what I am feeling at that time. 
Just like in that other poem. It is going to be what I am feeling at that moment. If I am feeling a rush you know, if I am feeling triumphant he is going to hit a home run that is going to be talked about for ages. But if I am down and I just got some bad news, something like that, he is going to strike out again. And I have no control for that and I don't know when I will get to. I'm going to have about a half an hour to write tomorrow I think. I don't know if I will get to that part or not. So I guess Casey is hoping I am in a good mood.

Fortunately for Casey, on the day Doug finished the poem he began his protocol by saying, "I am feeling pretty hyper now so if he finishes it, hitting a home run to finish it." After writing a triumphant conclusion to the poem, Doug said, "I mean like I said, when I sat down here I was in a good mood. And what'd I say last night? If I am in a good mood, he is going to hit the ball over there and I am in a good mood and that is what he did."

Doug's use of writing for emotional mediation in his two senioryear English classes contrasted with his reports of his writing experiences in prior years where the five-paragraph essay had been the staple of writing instruction. The emotionally supportive environment of both classes appeared to enable him to use writing as a tool for development and to support that instrumental use with the reward of both good grades and good personal feelings from his teachers and classmates.

On several occasions Doug referred to getting a "rush" while writing, saying that he deliberately created moments of discovery by "trying to keep out of my mind what is going to happen in the end." We categorized such statements as epiphanies in that Doug would use his writing to come upon a sudden realization. After reading some lines from early in his journey poem, Doug said, "The next stanza starts talking about the dragon coming up, I didn't know that until the two lines into it, 'the quiet now is broken, together with the light.' I still didn't know then that he is going to face the dragon." When the dragon finally appeared Doug thought that "If there is a dragon here, there can be magic in it. You know, heck, we are using the dragon, why can't we use magic? I don't whether the M or not, but as soon as I thought magic, Merlin popped into my head. 'I looked at left to see a Merlin.' " These moments of insight provided a great deal of excitement for Doug both in his writing and during his recounting of his process.

Doug's senior-year English classes thus allowed opportunities for him to experience the expressive functions of writing. His teachers 
encouraged exploratory writing in ways his teachers in prior years had not, allowing Doug the chance to use writing as a tool for inquiry and exploration. With the assessment practices of his teachers allowing for students to make choices about what to submit for grades, Doug could, on selected occasions, write without concern for how others would judge the final form. Even within the constraints of form, Doug would periodically write for discovery, even to the point of blocking out possible sequences of events, to get a rush from the moment of production. Writing thus served as an expressive, mediational tool for Doug during his senior-class writing.

Doug's production of emotionally mediational writing came in the context of his teachers' assessment:

When I wrote, I wasn't writing to them [my friends]. I wasn't writing to impress them. I wasn't writing to impress the teacher. I was writing, basically, I was writing what I thought was what I wanted to write. I had the assignment, yeah, I needed to write something, and when you are writing something for a teacher, you cannot help but think about how it is going to be received, and whether it is going to be what she is looking for. But I know that when I wrote those poems, stories, and plays, it was what I was looking for.

When asked "If writing the stuff had gotten you a C, would you have cared? Would it have mattered in the way you wrote?" he replied, "It would have mattered. ... Because you know, I am going to be interested in good grades.... Man, these grades will go on your transcript, affect your grade point average. I could not afford to feel good about myself, the way I was writing, but still take a $C$ in English class because of it.... If they were going to look for something different, I probably would have had to have changed it." The values of his teachers, then, allowed him to adopt writing for his particular purposes. Their assessment practices, which provided the context for his choices, supported his use of writing for personal exploration. They also provided the social context for Doug's choice of genres, thus helping to channel his expressive uses of writing into specific designative forms.

\section{Expressive Uses of the Research Process}

Doug's involvement in the research was not simply a matter of his being an unusually cooperative student. Doug found his participation to be an important source of mediation, complementing his uses of 
writing in his English classes. His think-aloud sessions served as somewhat of an oral journal for him as he would take out his writing and talk about it, often addressing me as the audience for his thinking. Such occasions took place most frequently during portions of his protocol that received Level I codes of Retrospective. Segments coded Thinking-Aloud as Tool revealed Doug reflecting on how beneficial he found the protocol process. On one occasion he said, "I would like to take the chance to thank you for letting me do this because it is kind of neat to get my thoughts out.... It is kind of neat to have someone to talk to like this. And after I am done with the experiment, I will keep doing this, I will keep talking in the recorder. Leave some sort of physical memory behind of me, but other than that it helps to get my voice out. It is something that I can't always talk about to other people." One might think from these statements that I frequently played the role of therapist for Doug, but in fact we had little personal contact prior to, or during, Doug's think-aloud composing. I spoke with Doug and other students initially to acquaint them with the project and provide instructions on how to operate the tape recorders and provide a think-aloud, and observed several of Doug's classes, but otherwise we did not develop a close relationship during the research (although we have stayed in touch since the study).

Yet Doug developed a conception of the researcher that prompted a friendly, warm, extensive, and at times confessional protocol. Rather than being a neutral means of data elicitation, the tape recorder, in its perceived embodiment of a benevolent researcher, served as a cultural tool in the social construction of the protocol data. Typically, concern for researcher effects comes through personal transactions (Rosenthal, 1966), yet the protocol provided by Doug suggests that even "neutral" media such as tape recorders can become anthropomorphic representations of human qualities when so ascribed by research participants, and thus serve as tools that help mediate their thinking in highly social ways. Doug's conception of the researcher seemed in part an embodiment of the warm qualities of his Creative Writing and British Literature/Writing Workshop teachers, possibly accounting to some extent for the content of the protocols that emerged.

Doug's reference to his recorded thoughts as a means through which he could "Leave some sort of physical memory behind of me, but other than that it helps to get my voice out" reveals the way in which the research process served both designative and expressive functions for him. As Wells (1996) points out, a material text furnishes a point of reference for continued reflection, which the "physical 
memory" of the tape recording provided. Yet Doug's need to get his voice out was also served by the research process, enabling him to think through his purposes for writing in ways he hadn't previously found available.

\section{Expressive Composing as a Developmental Tool}

Doug's experiences in his senior-year English class, including his participation in the research, provided him with tools that he was still using 3 years after the data collection. Doug went to college immediately after graduating but dropped out within a year because he was not prepared for the rigors of college academics. In high school he had worked hard enough to get good grades, but no harder: "The only time I did homework was doing this [writing for English class], which I enjoyed because this was becoming an outlet for me.... Other than that, maybe a few minutes a night finishing up some math stuff, other than that, no homework, no studying, and I got by just fine," getting $A^{\prime}$ s in all courses but one in his junior and senior years. In college, he failed Introduction to Music and did poorly in other classes. The only classes he performed well in were his English classes: "I believe this stuff [his senior year writing] helped me in the fact that when I got in there and it was time to write a paper, it was very easy for me. . . I had a very easy time thinking it through in my head, and the essay just came flowing out." In his other college classes-mostly large introductory courses that required note taking and content examshis lack of the study habits required for mastering content knowledge resulted in poor performances that led him to withdraw from school.

After withdrawing from college, Doug took a job in the university's athletic department. His job provided him with an electronic mail account that he found allowed him to employ writing in much the same way he used it during his senior year of high school. He had a friend attending a university in Pennsylvania and developed an E-mail correspondence with one of her roommates:

When I write to [her] I never hold anything back. I can write just real freely to her and when I am typing on the computer, and I just start going, it amazes me what will come out. It is like a soul-searching method where the stuff that was inside of me that I wouldn't have just sat down and started writing out for no particular reason, I am writing to [her], and it comes out, and it is amazing.... And she reciprocates. 
She talked about a lot of problems. And when there is a third party involved that has nothing to do with you and your problems and they give you a viewpoint that is totally unconnected with anything in the situation, it helps a lot. And I have helped her through some tough times. She helped me through some tough times.

Doug explicitly credited his senior-year writing for his use of E-mail for emotional mediation 3 years later:

Doug: I think that as these assignments started and this [research] study started when I was in that English class, that was a new thing for me that has continued today, and I am sure it will continue.

Q: Really?

Doug: Yes. I see that as being a point in my life, because I had never written before. I had never tried to write those kinds of things out, and I did it there and ever since then, I have been able to- that has just opened up a lot of new things for me. My writing an E-mail to a friend in Pennsylvania is not like me writing a poem. But the fact is, I am not speaking it to somebody. So that is me writing as an outlet. And that is so healthy for me. I mean, me being able to go in there and writing on e-mail, is so good, because I start talking to [her]. ... I know when I sit down and start typing to her and start typing about situations, I don't know what it is when I say them, but I know that once I start typing, a lot of my feelings come out. And it does every time. It just doesn't seem to fail.

As Doug noted, both his senior-year writing and his participation in the research contributed to his long-term use of writing as a tool for emotional mediation. During his follow-up interview he said of his protocol production,

Doug: Speaking into a tape recorder, and actually getting my thoughts out, not necessarily on paper, but getting my thoughts out to where I was hearing instead of just having it pass through my head, that was a different experience for me. Like I said, that was something different. Like I said, that is easier today.

Q: You said at one point that you were going to keep doing that even after the study was over.

Doug: I never did continue doing that, but what I have done since, what I am able to talk openly with some friends, and the way I am able to write down my feelings, I can sit here and directly relate my experience speaking to a tape recorder. You know, when we get into having more openness with friends. It tickles me to death when I sit down and think about it. 
Doug's use of writing as a mediational tool persisted well beyond his graduation and completion of the research. His own reflective nature provided him with consonance with writing for mediational purposes. Key to his use of writing as a medium for emotional reflection was his location of a third-party reader, such as his teacher, a researcher listening to his tape recordings, or an e-mail correspondent (whom he finally met after 6 months of writing, ultimately adding phone calls to his mediational repertoire).

Doug was able to appropriate a cultural tool, writing, in the way in which his teachers intended, even adapting it to new uses when he discovered the technology of e-mail. Yet other students in his classes did not develop the degree of consonance with mediational writing that he did, thus pointing to the need to account for his agency in tool use. All students in both classes found themselves within the same semiotic framework. As Doug pointed out, however, many students regarded Creative Writing as a "blow off" class in which they could write a few poems and get an easy A, because their teacher was supportive rather than critical of their efforts. Similarly, not all students in his British Literature/Writing Workshop responded well to the structure of the class, preferring to have assignments with clearer, more conventional expectations. Furthermore, Doug was the only student who completed the study, with most others dropping out before producing any protocol data. Doug's experiences thus reveal the potential for writing to serve as a source of meaning, rather than providing generalizable evidence that applies to all writers.

\section{DISCUSSION}

The data provided by Doug suggest that the conflict outlined by Murray (1980) and others between process and product, between the expressive and designative functions of writing, unnecessarily fragments composition theory into a competition between what are actually two complementary aspects of meaning construction available in and through writing. Doug's experiences suggest the importance of both and the relationship between the two. His attention to his reciprocal relationships between both himself and other writers and readers of his own prose supports a social-interactive perspective on a designative emphasis (e.g., Nystrand, 1986). Doug illustrates the designative potential of written texts as a source of meaning through his 
attention to the lyrics of Garth Brooks and the manner in which they stimulated great rumination on his own life situations, and by his subsequent attention to the form into which he rendered his own thoughts, both for his own continued reflection and for the resonance and stimulation it would provide his readers. The importance of the designative function was emphasized by his readers, in particular by Ms. McDonald in her attention to the need for communicating with chosen audiences and preparing for college expectations. Doug appeared less concerned with developing a facility with the conventions of college writing than he was with producing writing that could affect his chosen readers, as indicated by his careful attention to the details of the written form of the pieces he intended to share with others. Doug sought to move others as he himself was moved by writers he admired and crafted his writing to achieve that goal. His experience in making a girl cry in response to one of his poems seemed a key moment in his understanding of the importance of the final form of his texts.

Doug also found that his writing and thinking aloud served mediational purposes provided through the expressive function of composing. His expressive writing is illustrated by his writing of poems that expressed his feelings for the moment, pieces that he felt revision would compromise. On these occasions Doug deliberately used writing as a tool for exploring his thoughts and feelings with little regard for, and at times with resistance to, concerns about the final form of the piece.

Although the protocol and interviews at times identified Doug's concern for the expressive or designative potential of writing exclusive of the other, it also appeared that his expressive use of writing often came in combination with his recognition of its designative potential. His remarks about his use of the protocol procedure and his subsequent use of electronic mail communication suggested that to him the experiences provided at once a mediational purpose in exploring his thoughts and feelings and a designative purpose in providing him with a recorded account of those thoughts that he could either reflect on personally or share with a trusted third-party listener.

The perception that the expressive and designative functions of writing are in opposition is based on a conception of each as a sufficient perspective on human activity and psychological transformation. In contrast, the data provided by Doug suggest that the potential for constructing meaning in and through writing is a function of tool mediation, whether the tool is one that renders inner 
speech to public speech or designates meaning through a sign. I stress the potential for meaning construction through writing for two reasons. First, Doug had not used writing as a cultural tool prior to his senior year in high school; the purposes for writing stressed by his senior-year teachers were consonant with his own goals for personal exploration and communication and therefore helped him realize the mediational potential of writing. Second, a number of Doug's classmates in both classes performed erratically, with one of the original volunteers for the study missing class frequently, turning in little work, and ultimately failing Creative Writing. As argued following case studies of students composing through artistic means (Smagorinsky, 1995a, 1995b; Smagorinsky \& Coppock, 1994, 1995a, 1995b), writing can potentially serve as a mediational tool depending on how the confluence of the writer's goals and disposition operate within the constraints and affordances provided by the social context of writing.

Some occasions undoubtedly call for placing a greater emphasis on either the expressive or designative functions of writing, as when Doug wrote his poems and was resistant to revising them. This study suggests, however, that privileging one function over the other as a general principal denies writers the whole of the potential available in constructing meaning from the writing of others and through producing written texts of their own.

\section{APPENDIX}

Coding System

\section{LEVEL I}

Level I codes describe the general type of activity Doug was engaged in. Unlike conventional protocol participants who focus on thinking aloud while generating original text, Doug frequently engaged in revision of previously written texts and reflection about writing in general. The first level of codes, therefore, describes the broad type of thinking Doug was engaged in while thinking aloud. Such thinking fell into four categories:

Reflection $(R)$ : This code refers to occasions when Doug was not actively composing but was using pieces from his collected writing as a stimulus for reflection about his writing experiences, beliefs about writing, and purposes for writing. Example: "I just wrote a letter to one of my good friends in Pennsylvania/ and I guess that most kids I would say they would probably write a letter with a different state of mind than they would a paper for English or something./ I think I am kind of different because I have a lot of trouble 
revising in English and other writing classes where I have to write essays or something./ Whenever I write, I just write and if I see something that is wrong with it, I will go back and change it. / But once I am done with it, I am satisfied with it and I can't go back and change it because I think it is losing the meaning of what I wanted it to be and what I want it to be is me writing right then and not me going back and changing it two days later. / I want what I write down to be fresh off of my mind and not a compilation of two different days' thoughts."

Revision: retrospective (RR): This code refers to statements Doug made when he revised something composed during a prior writing session. Example: "I am now going to revise that poem I wrote in creative writing class about the chance that went by."

Generation $(G)$ : This code refers occasions when Doug was in the process of generating new text (this does not include revisions made during the generation of new text). Example: "Ok, I actually got the tape recorder here with me in process which is more what you wanted to do."

Revision: in process (RIP): This code refers to statements Doug made when he revised something he was in the process of composing for the first time. Example: "It twas the case today, it twas the case today, Casey, mighty Casey has scored today./ It twas the case today, the score that Casey raised./ No, $I^{\prime} m$ thinking about changing that line before, maybe if I put that line before that, yeah."

\section{LEVEL II}

Level II codes describe the specific activity revealed through Doug's thinking-aloud. The codes for Level II fall under three general headings: Designative Function, Expressive Function, and Other. The designative function is divided into the sections of Reciprocal Relationships and Formal Considerations. Each of these general headings includes a number of specific codes that are explained next.

\section{Designative Function}

The designative function includes Doug's attention to (a) reciprocity, or the specific types of effects Doug sought to have on readers; and (b) formal constraints on his writing. Segments identified as designative were further distinguished by a Level III code, explained after the delineation of all Level II codes.

Following are the designative codes. 


\section{APPENDIX Continued}

\section{Reciprocal Relationships}

General Effect (GE): This code refers to the overall effect of writing on a reader; usually these codes came when Doug would speak of a reader without specifying a particular type of effect. Example: "I didn't want it to be the usual high school poem, I wanted it to be something you could read out of your English book and think boy, Lord Byron did a good job on that one, you know what I mean."

Sensory Effect (SE): This code refers to the reader's engagement with the images of the writing. Example: "And I think that is a pretty good quality, quality is the word I am looking for./ The good quality, to be able to write so little, but yet make it seem such a long time./ Because I want them to picture hours of walking through this tunnel, but I am not going to write fifty pages to depict hours of walking through the tunnel."

Emotional Effect $(E E)$ : This code refers to a concern for the emotional impact of the writing on the reader. Example: "I love writing poems like that. The one I told you about that I wrote about my friend, I actually made a girl in my creative writing class cry when she read that and you know, it felt good. It was such a neat feeling to know that something I wrote, something that I just wrote down on paper made someone cry. I mean hell, if that is not saying your poem is good, unless like she is crying because she is laughing so hard, but she wasn't laughing."

Thematic Effect (TE): This code refers to the degree to which the reader relates to a piece of writing, particularly in terms of the life themes represented. Example: "I want to read you the lyrics to a song./ It is called "The River' by Garth Brooks. / I don't know if you have heard it./ You know we [inaudible] our poem and the words in this poem really hit home to me and for a lot of other people and I just hope that someday, I can progress to the point where I can write something like this and have everyone be able to understand it and relate to it."

Appropriateness $(A)$ : This code refers to attention to word choice in terms of propriety. Example: "I can't say the batter grabs himself./ I would like to, but hey, this is school work."

Validity $(V)$ : This code refers to the degree to which a reader would find the substance of the writing valid relative to reality. Example: "I kind of don't like the second line in this. / 'The darkness seemed eternal as the chill of night sets in,'/ I don't know if I like 'the chill of night sets in,' you know if he is in this place for hours, then he is not going to know what time of day it is."

\section{Formal Considerations}

Intertextual Appropriation (IA): This code refers to occasions when Doug explicitly drew on a prior text to inform the text he was composing. Example: 
"As soon as I thought magic, Merlin popped into my head. 'I looked at left to see a Merlin.' I don't even know if a Merlin can be used as a noun meaning the equivalent of a wizard. I don't know if Merlin is just a name for a wizard that was popular or something. I may have been making up a new profession here. . . . I wanted [a character named Merlin] to be, I don't know, I picture him as an older fellow. You always picture wizards and stuff like that as guys with pointy hats, long gray beards and old. That is how I pictured him and when I say he winked, while showing a slight grin, you got this almost Santa Claus image of an old man winking at you. I like that. I like, it automatically makes him a good guy."

Form $(F)$ : This code refers to issues regarding stanza length, rhyme, and other writing decisions that concerned the formal expectations of his readership. Example: "[I'm going to] go over [the poem] real quick and see if there is anything I want to change in it to make it go a little bit smoother, but I am not going to change anything that would change the meaning."

Rhetorical Effect $(R E)$ : This code refers to the impact that the dramatic structure of the composition will have on the reader. Example: "I want to have that wrapping up line that does not necessarily come out and say he hit a homerun./ I want it to say, 'Everyone is happy./ Everyone is happy./ Casey is a hero, Casey hit the ball out.'/ Kind of like saving the part we all know would happen till the end."

Questions of Authority $(Q A)$ : This code refers to the degree of control readers and writers have over one another. Such statements included those in which Doug expressed his resistance to the authority of a reader over his writing. Example: "If there is one thing that a good writer does, it is not paying attention to what he thinks makes a good writer./ You have to just write what is on your mind, not follow guidelines./ That is something else that I feel very strongly about because in a way it is frustrating to get graded on writing, on what you have written, because in a way, it is almost like grading an opinion./ You know stories have opinions in them and the way you write is almost an opinion./ It is when you get graded on something you have written, it is frustrating."

\section{Expressive Function}

In addition to writing that was constrained by concerns for his readership, Doug also produced writing that he composed entirely for his own purposes (although he did turn some of this writing in to a teacher). Most such writing explored his emotional response to situations in his life, and Doug stated that to revise such writing would destroy it because he could not revise his feelings. Doug's expressive remarks fell under two categories, Expressive Uses of Writing and Expressive Uses of the Research Process. 


\section{APPENDIX Continued}

\section{Expressive Uses of Writing}

Emotional Mediation (EM): This code refers to occasions when Doug used writing to mediate his understanding of his emotions; such writing was not intended for an audience but rather served the immediate purpose of helping him to work through emotional problems. Example: "I know, another deep poem./ Well you know according to Ms. McDonald's theory I should be revising this before I turn it in, but you know I look at it and I can't./ I wrote this within the span of about 10 minutes./ That feeling, this inspiration hit me and I wrote it down and this is true feelings, this is what I feel or what I felt./ I was nuts there for a minute, man./ I wrote down this feeling that came over me and to go back and revise that now, I can't do that./ I would be changing this poem into something I wouldn't want it to be./ I want this poem to be as I said at the beginning of the tape, you know I don't like revising stuff because it is two completely different states of mind./ When I wrote this, like I said this feeling came over me./ I wrote it down, I wrote down the way I felt and today I might feel differently./ I don't want to ruin what I created then with that feeling, but what I feel now./ So I am going to turn it in like this."

Writing as Epiphany (WE): This code refers to occasions when Doug came to a sudden realization about himself or about how his writing would proceed. Example: "I wrote a page of this not knowing what was going to happen./ That almost makes writing more fun for me./ You read a story or you watch a movie and you are trying to figure out what is going to happen at the end./ Who killed this person./ What are they going to find at the end of this tunnel./ It is almost the same thing with me./ I am wanting to know what is going to happen at the end./ I am in control of the destiny, but it is still a rush for me to know what is going to happen."

Feeling of Authority (FA): This code refers to occasions when Doug described a feeling of power he would get when writing on a topic over which he had complete control; on some of these occasions the process of writing about the topic led him to achieve a feeling of personal power. Example: "I don't know, it is kind of an interesting assignment because like I say, you get this feeling of power./ You are in charge and that is something you can incorporate into a short story./ It is about a principal./ Making changes and you feel power and this is going to hopefully, something I would want to do is make this sound as if when you are reading it, you feel the power you know./ You feel this."

\section{Expressive Uses of the Research Process}

Throughout his protocol Doug addressed the researcher in a conversational way. Even though their actual face-to-face contact had been limited, 
Doug spoke very confidentially to the researcher about his life and writing. Doug appeared to imagine the researcher as a confidant, one with whom he could share intimate thoughts about himself and his relationships with others. Expressive Uses of the Research Process codes fell into the following category:

Think-Aloud as Tool (TAT): This code refers to occasions when Doug spoke about the process of participating in the research. Example: "I would like to take the chance to thank you for letting me do this because it is kind of neat to get my thoughts out. ... It is kind of neat to have someone to talk to like this. And after I am done with the experiment, I will keep doing this, I will keep talking in the recorder. Leave some sort of physical memory behind of me, but other than that it helps to get my voice out. It is something that I can't always talk to about to other people."

\section{Other}

Reread Text $(R T)$ : Reread codes are reciprocal because Doug takes the role of reader, at times playing the role of a hypothetical audience. The reread code refers to occasions when Doug reread a section of previously written text. Example: "I wrote this back in September and I will read what I have to you."

Positive Judgment (PJ): This code refers to a favorable evaluation of writing. In most instances judgment codes described Doug as a reader of his own writing. Example: "I think I am satisfied with the poem."

Incidental (I): Statements that were incidental to the act of composing. Example: "[It is] starting to sleet outside./ Man, it is cold."

Negative Judgment (NJ): This code refers to an unfavorable evaluation of writing. Example: "I have to be truthful with you, this is not a very good work of mine, and I don't particularly like it."

\section{LEVEL III}

Level III codes describe the specific type of reciprocity between reader and writer (Level II, 1-15). Reciprocity was represented in three categories:

Readers of Doug (RD): This code refers to occasions when Doug described the effect his own writing had on other readers. Example: "I want people to be able to relate to my works. I am getting a bunch of papers back in creative writing tomorrow and I am going to read you some of those./ There is one in there that I wrote that I really believe people can relate to."

Doug as Reader of Others (DRO): This code refers to occasions when Doug described the effect of other writers on himself. Example: "I don't know if you have ever read 'Casey at the Bat,' but that poem is the only one that has ever stood out in my mind as one I remember, you know./ The poem is something 


\section{APPENDIX Continued}

I can relate to and it is something that I enjoyed reading and it is very easy to read."

Doug as Reader of Himself (DRH): This code refers to occasions when Doug described his own response to his own writing. Example: "After I wrote it and went back and read it back to you, even for me, I grew excited./ I knew he was going to hit it out, but I was getting excited and that shows me that I did a good job."

\section{NOTE}

1. Throughout this article I will use the term speech rather than language. Rieber and Carton (1987) argue in their Editor's Foreword to The Collected Works of L. S. Vygotsky: Vol. 1. Problems of General Psychology, Including the Volume Thinking and Speech that Vygotsky "vigorously distinguished speech from language" (p. vi), with speech representing a dynamic process of rendering sense (inner, fluid, psychological) into meaning (public, fixed, social), and language describing the grammatical and semantic system construed from the observation of speech. Their translation of the title (and subsequent text) of Myschlenie I Rech' (1934) as Thinking and Speech is, they argue, truer to both Vygotsky's terms and intentions than the previous title of Thought and Language (1962, 1986), a view shared by Cazden (1988, p. 99) among others.

\section{REFERENCES}

Ackerman, J. M. (1993). The promise of writing to learn. Written Communication, 10, 334-370.

Applebee, A. N. (1981). Writing in the secondary school: English and the content areas (NCTE Research Report No. 21). Urbana, IL: National Council of Teachers of English.

Atwell, N. (1987). In the middle: Writing, reading, and learning with adolescents. Portsmouth, NH: Heinemann.

Braddock, R., Lloyd-Jones, R., \& Schoer, L. (1963). Research in written composition. Champaign, IL: National Council of Teachers of English.

Britton, J., Burgess, T., Martin, N., McLeod, A., \& Rosen, H. (1975). The development of writing abilities: 11-18. London: Macmillan.

Cazden, C. B. (1988). Classroom discourse: The language of teaching and learning. Portsmouth, NH: Heinemann.

Emig, J. (1971). The composing processes of twelfth graders (NCTE Research Report No. 13). Urbana, IL: National Council of Teachers of English.

Emig, J. (1977). Writing as a mode of learning. College Composition and Communication, $28,122-128$. 
Fulwiler, T. (1989). Responding to student journals. In C. M. Anson (Ed.), Writing and response: Theory, practice, and research (pp. 149-173). Urbana, IL: National Council of Teachers of English.

Hillocks, G. (1975). Observing and writing. Urbana, IL: National Council of Teachers of English.

Hillocks, G. (1986). Research on written composition: New directions for teaching. Urbana, IL: National Conference on Research in English.

Kahn, E., Walter, C. C., \& Johannessen, L. (1984). Writing about literature. Urbana, IL: National Council of Teachers of English.

Kirby, D., \& Liner, T. (1988). Inside/out: Developmental strategies for teaching writing (2nd ed.). Portsmouth, $\mathrm{NH}$ : Heinemann.

Langer, J. A., \& Applebee, A. N. (1987). How writing shapes thinking: A study of teaching and learning (NCTE Research Report No. 22). Urbana, IL: National Council of Teachers of English.

Marshall, J. D., Smagorinsky, P., \& Smith, M. W. (1995). The language of interpretation: Patterns of discourse in discussions of literature (NCTE Research Report No. 27). Urbana, IL: National Council of Teachers of English.

Martin, N. (1984). Writing across the curriculum: Pamphlets from the Schools Council/London Institute of Education W.A.C. project. Montclair, NJ: Boynton/Cook.

Moffett, J. (1968). Teaching the universe of discourse. Boston: Houghton Mifflin.

Murray, D. M. (1980). Writing as process: How writing finds its own meaning. In T. R. Donovan \& B. W. McClelland (Eds.), Eight approaches to teaching composition (pp. 320). Urbana, IL: National Council of Teachers of English.

Nystrand, M. (1986). The structure of written communication. Orlando, FL: Academic Press.

Rieber, R., \& Carton, A. S. (1987). Editors' foreword. In R. Rieber \& A. Carton (Eds.), N. Minick (Trans.), The collected works of L. S. Vygotsky, Vol. 1: Problems of general psychology (pp. v-vii). New York: Plenum.

Rosenblatt, L. M. (1978). The reader, the text, the poem: The transactional theory of the literary work. Carbondale: Southern Illinois University Press.

Rosenthal, R. (1966). Experimenter effects in behavioral research. New York: AppletonCentury-Crofts.

Rosenthal, R., \& Rosnow, R. L. (1975). The volunteer subject. New York: John Wiley.

Smagorinsky, P. (1995a). Constructing meaning in the disciplines: Reconceptualizing writing across the curriculum as composing across the curriculum. American Journal of Education, 103(2), 160-184.

Smagorinsky, P. (1995b). The social construction of data: Methodological problems of investigating learning in the zone of proximal development. Review of Educational Research, 65(3), 191-212.

Smagorinsky, P., \& Coppock, J. (1994). Cultural tools and the classroom context: An exploration of an alternative response to literature. Written Communication, 11, 283-310.

Smagorinsky, P., \& Coppock, J. (1995a). The reader, the text, the context: An exploration of a choreographed response to literature. Journal of Reading Behavior, 27, 271-298.

Smagorinsky, P., \& Coppock, J. (1995b). Reading through the lines: An exploration of drama as a response to literature. Reading $\mathcal{E}$ Writing Quarterly, 11, 369-391.

Taylor, C. (1985). Philosophy and the human sciences: Philosphical papers II. Cambridge, UK: Cambridge University Press. 
Vygotsky, L. S. (1934). Myshlenie i rech': Psikhologicheskie issledovaniya. Moscow and Leningrad: Gosudarstvennoe Sotsial'no-Ekonomicheskio Izdatel'stvo.

Vygotsky, L. S. (1962). Thought and language. Cambridge, MA: MIT Press.

Vygotsky, L. S. (1986). Thought and language (A. Kozulin, Ed. and Trans.). Cambridge, MA: MIT Press.

Vygotsky, L. S. (1987). Thinking and speech. In R. Rieber \& A. Carton (Eds.), N. Minick (Trans.), The collected works of L.S. Vygotsky, Vol. 1: Problems of general psychology. New York: Plenum.

Wells, G. (1996, February). Making meaning with text: A genetic approach to the mediating role of writing in activity. Paper presented at the Midwinter Conference of the Assembly for Research of the National Council of Teachers of English, A Vygotsky Centennial: Vygotskian Perspectives on Literacy Research, Chicago.

Wertsch, J. V. (1996, February). Vygotsky's two minds on the nature of meaning. Paper presented at the Midwinter Conference of the Assembly for Research of the National Council of Teachers of English, A Vygotsky Centennial: Vygotskian Perspectives on Literacy Research, Chicago.

Peter Smagorinsky is an associate professor of English Education at the University of Oklahoma. Funded by a grant from the NCTE Research Foundation, he is currently studying multimedia composing in a high school English class. Through the National Research Center for English Learning and Achievement (CELA), he is also studying the transition that English teachers make from preservice programs to the work force. With Michael W. Smith, he is coeditor of Research in the Teaching of English and past chair of NCTE's Assembly for Research. Direct E-mail correspondence to psmagorinsky@ou.edu. 